Editor-in-Chief

Victoria Chan-Palay - Singapore, Singapore

\title{
Editorial Board Members
}

Dag Aarsland - Stavanger University Hospital, Stavanger, Norway

Suvarna Alladi - National Institute of Mental Health and Neuro Sciences,

Karnataka, India

Marta Altieri - Policlinico Umberto I Clinica Neurologica, Rome, Italy

Stefanie Auer - Donau-Universität Krems, Bad Ischl, Austria

Clive Ballard - Wolfson Centre for Age-Related Diseases, Exter, UK

B. Lynn Beattie - UBC Hospital, Vancouver, BC, Canada

Jean-Christoph Bier - Université Libre de Bruxelles, Brussels, Belgium

Henry Brodaty - Prince of Wales Hospital, Randwick, NSW, Australia

Richard Camicioli - University of Alberta, Edmonton, AB, Canada

Barbara Caracciolo - Karolinska Institutet, Stockholm, Sweden

Jeffrey L. Cummings - Cleveland Clinic, Las Vegas, NV, USA

Jean-François Dartigues - Université de Bordeaux, Bordeaux, France

Mony J. de Leon - NYU School of Medicine, New York, NY, USA

Rachelle S. Doody - Baylor College of Medicine, Houston, TX, USA

Knut Engedal - Vestfold Health Trust, Tønsberg, Norway

Rosemary Fama - Stanford University School of Medicine, Stanford, CA, USA

Howard Feldman - University of California San Diego, La Jolla, CA, USA

Hans Förstl - Klinikum rechts der Isar, Munich, Germany

Samuel E. Gandy - Mount Sinai School of Medicine, New York, NY, USA

Serge Gauthier - McGill Centre for Studies in Aging, Verdun, QC, Canada

Lars Gustafson - Lund University, Lund, Sweden

Mary N. Haan - University of California, San Francisco, CA, USA

Franz F. Hefti - Avid Radiopharmaceuticals, Inc., Philadelphia, PA, USA

Akira Homma - Center for Dementia Care Research and Training, Tokyo, Japan

Michael Hornberger - University of East Anglia, Norwich, UK

Paul G. Ince - Sheffield University Medical School, Sheffield, UK

Kurt A. Jellinger - Institute of Clinical Neurobiology, Vienna, Austria

Peter Johannsen - Rigshospitalet, Copenhagen, Denmark

(Continued on next page) 


\section{Dementia and Geriatric} Cognitive Disorders
(Continued)

\section{Editorial Board Members}

Yogeshwar Kalkonde - Society for Education, Action and Research in

Community Health, Gadchiroli, India

Dan Kaufer - The University of North Carolina, Chapel Hill, NC, USA

Ki Woong Kim - Seoul National University, Bundang, South Korea

John Kwok - Neuroscience Research Australia, Sydney, NSW, Australia

Feng Lin - University of Rochester Medical Center, Rochester, NY, USA

Kiyoshi Maeda - Kobe Gakuin University, Kobe, Japan

Colin L. Masters - The University of Melbourne, Melbourne, VIC, Australia

Bruce L. Miller - University of California, San Francisco, CA, USA

Eneida Mioshi - University of East Anglia, Norwich, UK

Urs P. Mosimann - University Hospital of Old Age Psychiatry,

Münchenbuchsee, Switzerland

Hiroaki Naritomi - Senri Chuo Hospital, Osaka, Japan

Tze-Pin Ng - National University Hospital, Singapore, Singapore

Jean-Marc Orgogozo - CHU Pellegrin, Université de Bordeaux, Bordeaux, France

Marian B. Patterson - Case Western Reserve University, Cleveland, OH, USA

Jordi Pérez-Tur - Institut de Biomedicina de València-CSIC, Valencia, Spain

Donald L. Price - Johns Hopkins University, Baltimore, MD, USA

Ramit Ravona-Springer - Sheba Medical Center, Ramat Gan, Israel

Barry Reisberg - Alzheimer's Disease Center, New York University, New York, NY, USA

Karen Ritchie - French National Institute of Medical Research, Montpellier, France

Gustavo C. Roman - Methodist Neurological Institute, Houston, TX, USA

Ingmar Rosén - Lund University Hospital, Lund, Sweden

Martin N. Rossor - National Hospital for Neurology and Neurosurgery, London, UK

Eric Salmon - Centre Hospitalier Universitaire de Liège, Liège, Belgium

Philip Scheltens - VU University Medical Center, Amsterdam, The Netherlands

Marianne Schultzberg - Karolinska Institutet, Stockholm, Sweden

Nobuto Shibata - Juntendo University School of Medicine, Tokyo, Japan

Melissa Slavin - University of New South Wales, Sydney, NSW, Australia

Janine Stein - University of Leipzig, Leipzig, Germany

Hikka Soininen - Kuopio University Hospital, Kuopio, Finland

Masatoshi Takeda - Aino University, Osaka, Japan

Toshihisa Tanaka - Osaka University, Osaka, Japan

Edmond Teng - University of California UCLA, Los Angeles, CA, USA

Katsuya Urakami - Tottori University, Yonago, Japan

Esther van den Berg - Erasmus MC, Rotterdam, The Netherlands

Frans R.J. Verhey - University Hospital of Maastricht, Maastricht, The Netherlands

Gunhild Waldemar - Rigshospitalet, Copenhagen University Hospital,

Copenhagen, Denmark

Christian Wienbruch - University of Konstanz, Konstanz, Germany

Bengt Winblad - Karolinska University Hospital, Stockholm, Sweden

\section{KARGER}


No. 1-2

Original Research Articles

1 Genetic Variation in Genes Underlying Diverse Dementias May Explain a Small Proportion of Cases in the Alzheimer's Disease Sequencing Project

Blue, E.E.; Bis, J.C.; Dorschner, M.O.; Tsuang, D.W. (Seattle, WA); Barral, S.M. (New York, NY); Beecham, G. (Miami, FL); Below, J.E. (Nashville, TN); Bush, W.S.; Butkiewicz, M. (Cleveland, OH); Cruchaga, C. (St. Louis, MO); DeStefano, A.; Farrer, L.A. (Boston, MA); Goate, A. (New York, NY); Haines, J. (Cleveland, OH); Jaworski, J. (Miami, FL); Jun, G. (Boston, FL); Kunkle, B. (Miami, FL); Kuzma, A. (Philadelphia, PA); Lee, J.J. (New York, NY); Lunetta, K.L.; Ma, Y. (Boston, MA); Martin, E. (Miami, FL); Naj, A. (Philadelphia, PA); Nato, A.Q.; Navas, P.; Nguyen, H. (Seattle, WA); Reitz, C.; Reyes, D. (New York, NY); Salerno, W. (Houston, TX); Schellenberg, G.D. (Philadelphia, PA); Seshadri, S. (Boston, MA); Sohi, H.; Thornton, T.A. (Seattle, WA); Valadares, O.(Philadelphia, PA); van Duijn, C. (Rotterdam); Vardarajan, B.N. (New York, NY); Wang, L.-S.

(Philadelphia, PA); Boerwinkle, E. (Houston, TX); Dupuis, J. (Boston, MA); Pericak-Vance, M.A. (Miami, FL); Mayeux, R. (New York, NY) Wijsman, E.M. (Seattle, WA) on behalf of the Alzheimer's Disease Sequencing Project

18 Use of Vitamin K Antagonists and Brain Morphological Changes in Older Adults: An Exposed/Unexposed Voxel-Based Morphometric Study

Brangier, A. (Angers); Celle, S.; Roche, F. (Saint-Etienne/Lyon); Beauchet, O.; Ferland, G. (Montreal, QC); Annweiler, C. (Angers/London, ON)

27 Prevalence, Recognition, and Treatment of Dementia in Assisted Living Facilities

Sutovsky, S.; Kralova, M.; Siarnik, P.; Turcani, P. (Bratislava)

38 Characteristics of Mild Cognitive Impairment Using the Thai Version of the Consortium to Establish a Registry for Alzheimer's Disease Tests: A Multivariate and Machine Learning Study

Tunvirachaisakul, C.; Supasitthumrong, T.; Tangwongchai, S.; Hemrunroj, S.; Chuchuen, P.; Tawankanjanachot, I.; Likitchareon, Y.; Phanthumchinda, K.; Sriswasdi, S.; Maes, M. (Bangkok)

49 Incremental Validity of Montreal Cognitive Assessment Index Scores in Mild Cognitive Impairment and Alzheimer Disease Goldstein, F.C.; Milloy, A.; Loring, D.W. (Atlanta, GA); for the Alzheimer's Disease Neuroimaging Initiative

56 Predictors of Rapid Cognitive Decline in Patients with Mildto-Moderate Alzheimer Disease: A Prospective Cohort Study with 12-Month Follow-Up Performed in Memory Clinics Tchalla, A.E.; Clément, J.-P.; Saulnier, I.; Beaumatin, B.; Lachal, F.; Gayot, C.; Bosetti, A.; Desormais, I.; Perrochon, A.; Preux, P.-M.; Couratier, P.; Dantoine, T. (Limoges)

66 Associations of Pulse and Blood Pressure with Hippocampal Volume by APOE and Cognitive Phenotype: The Alzheimer's Disease Neuroimaging Initiative (ADNI)

Ngwa, J.S.; Fungwe, T.V.; Ntekim, O.; Allard, J.S.; Johnson, S.M.; Castor, C.; Graham, L.; Nadarajah, S.; Gillum, R.F.; Obisesan, T.O. (Washington, DC)
79 Scores Obtained from a Simple Cognitive Test of Visuospatial Episodic Memory Performed Decades before Death Are Associated with the Ultimate Presence of Alzheimer Disease Pathology

Robinson, A.C. (Salford); McNamee, R. (Manchester); Davidson, Y.S. (Salford); Horan, M.A.; Snowden, J.S. (Manchester); McInnes, L. (Newcastle upon Tyne); Pendleton, N.; Mann, D.M.A. (Salford)

91 Quality of Life in People with Young-Onset Alzheimer's Dementia and Frontotemporal Dementia

Hvidsten, L. (Tønsberg); Engedal, K. (Tønsberg/Oslo); Selbæk, G. (Tønsberg/ Ottestad/Oslo); Wyller, T.B. (Oslo); Bruvik, F. (Bergen); Kersten, H. (Skien)

105 Functional Disconnectivity during Inter-Task Resting State in Dementia with Lewy Bodies

Chabran, E.; Roquet, D.; Gounot, D.; Sourty, M.; Armspach, J.-P.; Blanc, F. (Strasbourg)

121 Risk Factors and Outcomes of Delirium in Older Patients Admitted to Postacute Care with and without Dementia Gual, N. (Barcelona); Morandi, A. (Cremona/Brescia); Pérez, L.M. (Barcelona); Brítez, L. (Barcelona/Hospitalet de Llobregat); Burbano, P.; Man, F.; Inzitari, M. (Barcelona)

No. 3-4

Review Article

131 A Systematic Review and Meta-Analysis of the Effectiveness of Acetylcholinesterase Inhibitors and Memantine in Treating the Cognitive Symptoms of Dementia

Knight, R. (London); Khondoker, M. (Norwich); Magill, N.; Stewart, R.; Landau, S. (London)

Original Research Article

152 Cerebrospinal Fluid BACE1 Activity and sA $\beta P P \beta$ as Biomarker Candidates of Alzheimer's Disease

Alexopoulos, P. (Patras/Munich); Thierjung, N.; Grimmer, T.; Ortner, M. (Munich); Economou, P.; Assimakopoulos, K.; Gourzis, P. (Patras); Politis, A. (Athens/Baltimore, MD); Perneczky, R. (Munich/London); The Alzheimer's Disease Neuroimaging Initiative

162 Effect of Emotion and Type of Encoding on Memory for Actions: Verbal and Subject-Performed Tasks Borg, C. (Saint-Priest-en-Jarez/Lyon/Bron); Bouazza, Z. (Bron); Godeau, M. (Saint-Priest-en-Jarez/Bron); Getenet, J.-C. (Saint-Priest-en-Jarez); Chainay, H. (Bron)

180 Anxiety Symptoms in Older Adults with Depression Are Associated with Suicidality Bakkane Bendixen, A. (Oslo/Toensberg); Engedal, K. (Toensberg/Oslo); Selbæk, G. (Toensberg/Oslo/Ottestad); Hartberg, C.B. (Oslo)

190 Cognitive Reserve and Social Capital Accrued in Early and Midlife Moderate the Relation of Psychological Stress to Cognitive Performance in Old Age Ihle, A.; Oris, M.; Sauter, J.; Rimmele, U.; Kliegel, M. (Geneva)

\section{KARGER}

E-Mail karger@karger.com www.karger.com
(C) 2018 S. Karger AG, Basel

Access to full text and tables of contents, including tentative ones for forthcoming issues: www.karger.com/dem_issues 
Fully Automatic Speech-Based Analysis of the Semantic Verbal Fluency Task

König, A. (Nice); Linz, N.; Tröger, J. (Saarbrücken); Wolters, M. (Edinburgh); Alexandersson, J. (Saarbrücken); Robert, P. (Nice)

210 The Protective Effect of Cantonese/Mandarin Bilingualism on the Onset of Alzheimer Disease

Zheng, Y.; Wu, Q.; Su, F.; Fang, Y.; Zeng, J.; Pei, Z. (Guangzhou)

220 Distinct Clinical Features and Outcomes in Motor Neuron Disease Associated with Behavioural Variant Frontotemporal Dementia

Cortés-Vicente, E.; Turon-Sans, J. (Barcelona/Madrid); Gelpi, E. (Barcelona/ Vienna); Clarimón, J. (Vienna/Barcelona); Borrego-Écija, S. (Barcelona); Dols-Icardo, O.; Illán-Gala, I.; Lleó, A.; Illa, I.; Blesa, R. (Barcelona/Madrid); Al-Chalabi, A. (London); Rojas-García, R. (Barcelona/Madrid)

232 Sleep Disturbance and the Risk of Cognitive Decline or Clinical Conversion in the ADNI Cohort

Mecca, A.P. (New Haven/West Haven); Michalak, H.R.; McDonald, J.W.; Kemp, E.C.; Pugh, E.A.; Becker, M.L. (New Haven, CT); Mecca, M.C. (West Haven, CT/New Haven, CT); van Dyck, C.H. (New Haven, CT); The Alzheimer's Disease Neuroimaging Initiative (ADNI)

243 Lower Cognitive Function in Older Patients with Lower Muscle Strength and Muscle Mass

van Dam, R.; Van Ancum, J.M.; Verlaan, S.; Scheerman, K.; Meskers, C.G.M. (Amsterdam); Maier, A.B. (Amsterdam/Melbourne, VIC)

\section{No. 5-6}

Review Article

353 Quantitative Mobility Assessment for Fall Risk Prediction in Dementia: A Systematic Review

Dolatabadi, E.; Van Ooteghem, K.; Taati, B.; Iaboni, A. (Toronto, ON)

Original Research Articles

251 Gait Variability Can Predict the Risk of Cognitive Decline in Cognitively Normal Older People

Byun, S. (Seongnam/Seoul); Han, J.W. (Seongnam); Kim, T.H. (Wonju); Kim, K. (Seoul); Kim, T.H.; Park, J.Y.; Suh, S.W. (Seongnam); Seo, J.Y. (Jinju); So, Y. (Seongnam); Lee, K.H. (Busan); Lee, J.R.; Jeong, H. (Seongnam); Jeong, H.-G. (Seoul); Han, K.; Hong, J.W. (Seongnam); Kim, K.W. (Seongnam/Seoul)
262 Etoricoxib and Diclofenac Might Reduce the Risk of Dementia in Patients with Osteoarthritis: A Nation-Wide, Population-Based Retrospective Cohort Study Xue, Y.-H.; Peng, Y.-S.; Ting, H.-F.; Peijer Hsieh, J.; Huang, Y.-K.; Wang, Y.-H.; Chiou, J.-Y.; Wei, J.C.-C. (Taichung)

272 Multimorbidity Is Associated with Preclinical Alzheimer's Disease Neuroimaging Biomarkers

Mendes, A. (Geneva/Paris); Tezenas du Montcel, S.; Levy, M.; Bertrand, A.; Habert, M.-O.; Bertin, H.; Dubois, B.; Epelbaum, S. (Paris); INSIGHT-preAD study group

282 Increasing the Sensitivity of Functional Status Assessment in the Preclinical Range (Normal to Mild Cognitive Impairment): Exploring the IADL-Extended Approach

Fieo, R. (Gainesville, FL); Stern, Y. (New York, NY)

290 Influence of Age and Education on the Performance of Elderly in the Brazilian Version of the Montreal Cognitive Assessment Battery

Pinto, T.C.C.; Machado, L.; Bulgacov, T.M.; Rodrigues-Júnior, A.L.; Costa, M.L.G.; Ximenes, R.C.C.; Sougey, E.B. (Recife)

300 MACE for the Diagnosis of Dementia and MCl: 3-Year Pragmatic Diagnostic Test Accuracy Study Williamson, J.C.; Larner, A.J. (Liverpool)

308 The Pentagon Copying Test and the Clock Drawing Test as Prognostic Markers in Dementia with Lewy Bodies

Vergouw, L.J.M.; Salomé, M.; Kerklaan, A.G.; Kies, C. (Rotterdam); Roks, G. (Tilburg); van den Berg, E.; de Jong, F.J. (Rotterdam)

318 Combined Exercise and Cognitive Training System for Dementia Patients: A Randomized Controlled Trial Okamura, H. (Hiroshima); Otani, M. (Kudamatsu); Shimoyama, N. (Higashihiroshima); Fujii, T. (Shunan)

326 Clock Drawing Test: A Simple Scoring System for the Accurate Screening of Cognitive Impairment in Patients with Mild Cognitive Impairment and Dementia Rakusa, M. (Maribor); Jensterle, J. (Ljubljana); Mlakar, J. (Nova Gorica)

335 Effect of Apolipoprotein E \&4 Carrier Status on Cognitive Response to Acetylcholinesterase Inhibitors in Patients with Alzheimer's Disease: A Systematic Review and Meta-Analysis Cheng, Y.-C. (Taoyuan City/Taipei); Huang, Y.-C.; Liu, H.-C. (Taipei)

368 Acknowledgement to Reviewers
S. Karger

Medical and Scientific Publishers

Basel $\bullet$ Freiburg $\bullet$ Paris $\bullet$ London .

New York $\cdot$ Chennai $\cdot$ New Delhi $\cdot$

Bangkok $\cdot$ Beijing $\cdot$ Shanghai $\cdot$ Tokyo $\cdot$

Kuala Lumpur $•$ Singapore $\bullet$ Sydney

\begin{abstract}
Disclaimer
The statements, opinions and data contained in this publication are solely those of the individual authors and contributors and not of the publisher and the editor(s). The appearance of advertisements in the journal is not a warranty, endorsement, or approval of the products or services advertised or of their effectiveness, quality or safety. The publisher and the editor(s) disclaim responsibility for any injury to persons or property resulting from any ideas, methods, instructions or products referred to in the content or advertisements.

Drug Dosage

The authors and the publisher have exerted every effort to ensure that drug selection and dosage set forth in this text are in accord with current recommendations and practice at the time of publication. However, in view of ongoing research, changes in government regulations, and the constant flow of information relating to drug therapy and drug reactions, the reader is urged to check the package insert for each drug for any change in indications and dosage and for added warnings and precautions. This is particularly important when the recommended agent is a new and/or infrequently employed drug.
\end{abstract}

All rights reserved.

No part of this publication may be translated into other languages, reproduced or utilized in any form or by any means, electronic or mechanical, including photocopying, recording microcopying, or by any information storage and retrieva system, without permission in writing from the publisher or in the case of photocopying, direct payment of a specified fee to the Copyright Clearance Center (see "General Information")

(c) Copyright 2018 by S. Karger AG $\mathrm{CH}-4009$ Basel (Switzerland)

Printed on acid-free and non-aging paper (ISO 9706) 